DOI 10.37882/2223-2974.2021.03.14

\title{
ПРОБЛЕМНЫЕ АСПЕКТЫ СОВРЕМЕННОЙ СИСТЕМЫ УСТРОЙСТВА ДЕТЕЙ-СИРОТ И ДЕТЕЙ, ОСТАВШИХСЯ БЕЗ ПОПЕЧЕНИЯ РОДИТЕЛЕЙ, И ПРЕДЛОЖЕНИЯ ПО ИХ ПРЕОДОЛЕНИЮ
}

\section{PROBLEMATIC ASPECTS OF THE MODERN SYSTEM OF PLACEMENT OF ORPHANS AND CHILDREN LEFT WITHOUT PARENTAL CARE, B PROPOSALS FOR OVERCOMING THEM}

N. Kuznetsova O. Ryabova

E. Kovanov

Summary: The problem of children's placement for many years cannot find a compromise that satisfies all parties. This article is an analysis of the situation with the placement of orphans and children left without parental care. The authors suggest ways to solve the difficult problem facing the state and society to provide every child with a decent alternative to their native family if it is impossible to return there, or to provide a set of health measures for the parents of the withdrawn child to return the little person to the blood family. A child left without a family is deprived of many life benefits, the absence of which leads to disastrous consequences, the authors point out.

Keywords: family law, family, children left without parental care, orphans, the state, protection of the rights of the child.
$\mathrm{H}$ а протяжении всей человеческой истории детские годы напрямую формировали ключевые тенденции развития личности. Каждый в процессе взросления обязуется миновать данный этап, причём с приобретением полагающегося набора необходимых для социума качеств. Главенствующая роль родителя в становлении неоспорима: замена первого биологического наставника аналогичными кандидатами противопоказана в природной среде, поскольку наносит ущерб своему последователю. Подобная связь организмов обусловлена генетической предрасположенностью и происходит инстинктивно без внешнего вмешательства.

В результате стороннего контроля за состоянием ребёнка образуется неординарная ситуация: отсутствие места в жизни у молодого, обделённого требуемым вниманием поколения и сомнительная будущность уже взрослого представителя человечества в виду его своеобразного воспитания. Дальнейшая самостоятельная жизнь несовершеннолетнего вызывает сомнения, препятствуя своевременному формированию устойчивого мировоззрения и процессу обособления от остальных
Кузнецова Наталья Владимировна старший преподаватель, ФКОУ ВО «Владимирский юридический институт ФСИН России»

kuznezova-1963@mail.ru

Рябова Ольга Алексеевна

Преподаватель, ФКОУ ВО «Владимирский юридический uнстumym ФСИН России» frau.lelya2012@yandex.ru

Кованов Евгений Сергеевич

ФКОУ ВО «Владимирский юридический институт ФСИН России»

Аннотация: Проблема устройства детей долгие годы не может найти удовлетворяющий всем сторонам компромисс. Настоящая статья представляет собой анализ ситуации с устройством детей - сирот и детей, оставшихся без попечения родителей. Авторы предлагают пути решения непростой проблемы, стоящей перед государством и обществом по возможности обеспечить каждому ребенку достойную альтернативу родной семье в случае невозможности туда вернуться или обеспечить комплекс оздоровительных мероприятий для родителей изъятого ребенка, чтобы вернуть маленького человека в кровную семью. Оставшийся без семьи ребёнок лишается множества жизненных благ, отсутствие которых приводит к катастрофическим последствиям, указывают авторы.

Ключевые слова: семейное право, семья, дети, оставшиеся без попечения родителей, сироты, государство, защита прав ребёнка.

индивидуумов. Выходом из затруднительного положения может послужить переосмысление организации поддержки родителей, выполняющих функции по воспитанию собственных и приёмных детей, совместно с обозначением института семьи центральным звеном нового социально-политического курса. Важнейшими обязательными процедурами заявленных мероприятий станут повышение ответственности за уклонение от возложенных на себя обязанностей по уходу за ребёнком и приобретение, с последующим развитием, у родителей положенной семейно-бытовой культуры.

Большое количество законодательных инициатив: например, законопроект № 3138-6 “Об общественном контроле за обеспечением прав детей-сирот и детей, оставшихся без попечения родителей" [1], оставленный без движения, или законопроект№ 989011-7 “О внесении изменений в отдельные законодательные акты Российской Федерации в связи с принятием Федерального закона «О внесении изменений в Семейный кодекс Российской Федерации в целях укрепления института семьи»" [2], снятый с рассмотрения в виду отзыва субъек- 
том права законодательной инициативы, подчёркивает несостоятельность имеющейся системы детоустройства. Проблематика исследуемых подходов прослеживается в пренебрежении закреплёнными положениями закона и поверхностной проработанностью основных системообразующих порядков передачи несовершеннолетнего в новую семью. Реальная помощь подрастающему поколению заменяется на показательную причастность компетентных органов, демонстрируя при этом господство бюрократического аппарата над содержательным покровительством по отношению к ребёнку. Характерным следствием неудовлетворительного присмотра за лишёнными родительского контроля детьми является прямая взаимосвязь данного явления и отрицательного демографического роста внутри Российской Федерации.

Современное российское законодательство выделяет добровольные и принудительные случаи отказа родителей от ребенка.[3] При добровольной передаче детей, родители временно, а в большинстве случаев бессрочно переносят обязанность по воспитанию своего ребёнка на государство в лице специализированного учреждения. В принудительном порядке детей изымают из семей в случае угрозы для их здоровья и жизни. Злоупотребление родительскими правами, жестокое обращение с ребёнком, осуществление физического или психического насилия над ним, покушение на половую неприкосновенность, хроническая болезнь родителей в виде алкоголизма или наркомании, совершение умышленного преступления против члена семьи, опасность нахождения в семье по независящим от родителей обстоятельствам, а также при явных предпосылках к нанесению ущерба детской жизни или здоровью равнозначно разрушают нравственное здоровье малолетнего, безвозвратно дестабилизируя при этом внутреннее состояние субъекта.

Осознанный отказ от ребёнка или принудительное отобрание из семьи наносят непоправимый ущерб детскому организму. Безусловно, нахождение детей в специализированных детских учреждениях для сирот и временно находящихся под опекой государства детей лишь приближают условия проживания к домашним, а их деятельность направлена на воссоздание приближённых к семейному обустройству условий для воспитанников. Однако не стоит устанавливать паритет между искусственно созданным семейным объединением и каноничным нахождением в естественно комфортной среде.

По нашему мнению, основными задачами для регулирования высокого уровня социальной адаптации детей должны быть меры, связанные с оказанием со стороны государства максимально возможной помощи семьям, попавшим в трудную жизненную ситуацию и последующего возвращения туда изъятых детей, обозначение нового социально-семейного курса, поощряющего устоявшиеся ценности касательно непосредственной и нерушимой связи биологического родителя и ребёнка и порицающего любые отклонения от культуры воспитания, постинтернатное сопровождение выпускников государственных организаций для детей-сирот и детей, оставшихся без попечелния родителей.

Перечисленные выше установки могут повлиять на нежелательную конъюнктуру относительно устройства детей, оставшихся без попечения родителей, создать устойчивый базис безотлагательных семейно-правовых нововведений. Помимо приведённых предложений по уменьшению количества сирот и социальных сирот стоит напомнить, что социальное равенство и достойный уровень жизни граждан - прямая обязанность государства, которое пока не может полностью устранить данное социальное явление, хотя проводимые мероприятия повествуют о большой заинтересованности властных органов в этом вопросе.

В Законе Российской Федерации о поправке к Конституции РФ от 14 марта 2020 г. № 1-ФК3 «О совершенствовании регулирования отдельных вопросов организации и функционирования публичной власти» [4] уделено особое внимание актуальности вопросов образования и поддержания традиционной семьи, базируясь на том, что большинство законодательных актов, ориентированных на придание устойчивости семейным правоотношениям, непосредственно связаны с интересами несовершеннолетних детей. При этом законодатель поясняет, что благополучие ребенка определяется семейной благонадёжностью: в противном случае равновесие внутри семьи и всестороннее развитие несформировавшейся личности недостижимы.

Анализируя современное положение в рассматриваемой сфере, считаем возможным сделать некоторые выводы.

Полагаем, что для улучшения института устройства оставленных детей следует нормировать долженствующие условия для вступления в новую семью или в учреждения специального назначения. Целесообразность перехода не должна подменяться скорейшим вероятным переводом в безопасные условия проживания: качество выполняемой замены в идейном плане обязано оказывать содействие интересам ребёнка, а не занимающихся его делом посреднических органов.

Необходимо обеспечение непрерывного мониторинга выполняемой поддержки и надлежащей контрольной функции со стороны органов опеки и попечительства, общественности. Подразумевается неукоснительное преследование задач по предупреждению правонарушений в отношении несовершеннолетнего, препят- 
ствованию ухудшения самочувствия ребёнка, снижению количества негативных инцидентов, которые должны обеспечиваться не столько объёмом полномочий, сколько внутренними побуждениями субъектов, заинтересованных в полагающемся личностном становлении ребенка.

Учитывая тот факт, что ребенок в большинстве случаев беззащитен перед воспитывающим лицом, государство должно ужесточить ответственность для лиц и организаций, принимающих решение за ребёнка по передаче в семью: для органов опеки и попечительства, всех видов организаций, замещающих семейную самобытность, а также для биологических и приёмных родителей. При разработке и урегулировании вопросов материального обеспечения, денежного финансирования зачастую не учитывается реальная помощь нуждающимся детям. Например, повышенные штрафы для злоупотребляющих собственным наставническим положением органов и лиц, возмещение учреждением, приёмной семьёй затрат из регионального или федерального бюджетов за фиктивное усыновление, запреты на усыновление или занятия данной деятельностью субъектам, не прошедших специальную подготовку;

Считаем, что надлежит рассматривать профессиональные приёмные семьи, принимающие на обговорённый срок детей, родители которых оказались в затруднительной жизненной ситуации, как вариант их устройства. Европейская модель семейного развития предусматривает данную разновидность временных опеки или попечительства, в то время как в Российской Федерации распространение прекратилось на уровне предложений и призывов рекомендательного характера. Рассматриваемые элементы временного содержания детей являются универсальным решением, заслуживающим внимания. Наделённые исключительным статусом семьи будут проходить обязательную кадровую подготовку, квалификационный экзамен на выдачу временной лицензии, которую раз в несколько лет нужно будет подтверждать повторно, и иные испытания, закреплённые в методических документах. Центральным отличием от приёмной семьи будут: преимущественная направленность деятельности на возобновление воспитания родителями, записанными в свидетельстве о рождении, недопустимость возвращения ребёнка по инициативе принимающей стороны (за исключением несовместимости родителей и ребёнка), образцовая подготовленность в вопросах семьи введённого рабочего сегмента. Обеспечение денежными средствами будет осуществляться за счёт регионального или муниципального бюджетов, пожертвований частных лиц с полной финансовой отчётностью потраченных средств. Введённый в 2018 году специальный налоговый режим для самозанятых [5] был заимствован у зарубежных коллег: аналогичным образом следует поступить с родителями, выполняющих педагогические и общевоспитательные обязанности по трудовому договору.

Законодательством так же предусмотрен особый вид опеки или попечительства - патронатная семья [6], условия по организации и требования к которой установлены региональными нормативно-правовыми актами. По форме патронат напоминает профессиональную приёмную семью, только без наличия оплаты выполняемой деятельности, предусматривающей стабилизацию состояния оставленного ребёнка. Объединение патроната и профессиональной семьи с утверждением квот на их дозволенное количество в субъекте федерации послужит решающим фактором адаптирования правовых источников к нынешним реалиям. Одновременно с этим станет доступным внедрение унифицированной законодательной базы, разнящейся размером денежного обеспечения в зависимости от финансовых резервов региона.

Также необходимо проведение соразмерных вспомогательных мероприятий, нацеленных на надёжную и реальную поддержку родителей: добавочные денежные суммы к материнскому капиталу и расширение возможностей расходования этих средств, безвозмездное временное снижение налоговой нагрузки, льготы относительно проезда в общественном транспорте и иные ситуативные меры. Примером могут служить регионы, которые воплощают в жизнь законодательную практику в рамках социальной поддержки семьи.[9]

Государственная социальная политика должна обязывать к ведению борьбы за каждого покинутого ребёнка, не отступая от многовековых семейных идеалов. По информации Росстата за II квартал 2020 года приблизительно 2/3 молодых семей не могут себе позволить чтолибо, кроме затрат на еду и одежду [7], что отрицательно характеризует не только ситуацию на рынке труда, но и уязвимость всей семейной сферы касательно как самообеспечения, так и создания внутри семьи травмирующей ситуации.

Наиболее ультимативной мерой можно считать утверждение новой политико-социальной идеологии, не допускающей замены биологической семьи на других лиц по собственному волеизъявлению родителей. То есть добровольное отрешение от ребёнка должно сопровождаться суровым карательным аппаратом в области административных правоотношений: например, прекращение нахождения на общественных или государственно-гражданских должностях в сфере защиты прав несовершеннолетних, отстранение от профессий, связанных с детским обустройством. Принимаемое решение, о будущем ребёнке и ответственность за его воспитание подчиняется свободной воле родителей, потому невынужденный отказ от него претит как моральным, 
так и правовым устоям цивилизации. Это крайняя мера, которую стоит задействовать в случае неудачной реализации упомянутых выше предложений.

Представленные проекты нуждаются в осмыслении органами законодательной инициативы, по результатам которого значительно сократится часть проблемных аспектов действующей системы устройства детей, оставшихся без попечения родителей. Темпы укрепления позиций людей несовершеннолетнего возраста в пределах территорий субъектов РФ нуждаются в постоянном наблюдении и содействии со стороны общественных организаций, неравнодушных граждан и властных органов. Профилактические процедуры должны внедряться постепенно, чтобы нормализовать обстановку в каждом отдельном регионе, не обходя стороной присущие ему особенности. В первую очередь нужно бороться с причинами возникновения негативного эффекта "покинутых детей", потому что в противном случае ликвидировать неблагоприятные исходы не получится.

Согласно статистике Министерства просвещения, поступательные изменения в законодательстве демонстрируют положительную динамику в отношении возвращения в семейную воспитательную среду. Так, в соответствии с докладом директора Департамента государственной политики в сфере защиты прав детей Минпросвещения России, согласно информации представленной на сайте вышеуказанного ведомства, из числа выявленных за первые девять месяцев 2020 года детей - сирот и детей, оставшихся без попечения родителей, 72 \% переданы на семейные формы устройства и 23 \% были устроены в специализированные учреждения для данных категорий детей. Данные цифры, безусловно, являются обнадеживающими. Однако, достаточное количество таких детей входят в латентное число и это прямая недоработка государственных органов, несущих обязанность по отслеживанию и мониторингу указанных категорий несовершеннолетних лиц.

При этом, действующая система распределения детей, реализованная в Советском Союзе и сохранившая большинство догматов той эпохи, основным критерием считает возрастной компонент и особенности потенциала здоровья представленного индивида. Указанные тезисы предопределяют немотивированный перевод из одной организации в другую, разделение братьев и сестёр, пренебрежение желаниями ребёнка при перемене места проживания. Поиск уязвимостей современной системы детоустройства и редактирование проблемных мест, которые необходимы всем сформировавшимся правовым институтам, станут нерушимым фундаментом будущих преобразований, бесценным активом для следующих поколений при осуществлении усыновления (удочерения), опеки и попечительства.

В наши дни понятием "семья" многие пренебрегают, пытаясь обесценить значимость традиционного воспитания и поддержку близких людей. Взросление человека - наиважнейший период его существования, влияющий на все предпринятые им действия и решения в дальнейшем. Воспитание в семье не может быть заменено какими-то приближёнными условиями, потому что за каждого ребёнка до достижения совершеннолетия в первую очередь отвечают родители, и лишь после государство и иные лица. Современные защитные механизмы, которые надлежит скорректировать согласно сегодняшним вызовам, возникающим в правовом государстве, не в состоянии гарантировать должного отношения к несовершеннолетнему во всех затрагиваемых аспектах.

\section{ЛИТЕРАТУРА}

1. Законопроект №3138-6 “0б общественном контроле за обеспечением прав детей-сирот и детей, оставшихся без попечения родителей”. Система обеспечения законодательной деятельности. Электронный ресурc. URL - https://sozd.duma.gov.ru/bill/3138-6.

2. Законопроект № 989011-70 внесении изменений в отдельные законодательные акты Российской Федерации в связи с принятием Федерального закона “0 внесении изменений в Семейный кодекс Российской Федерации в целях укрепления института семьи". Система обеспечения законодательной деятельности. Электронный ресурc. URL - https://sozd.duma.gov.ru/bill/989011-7.

3. Семейный кодекс Российской Федерации от 29.12.1995 N 223-Ф3 (ред. от 06.02.2020) // «Собрание законодательства РФ», 01.01.1996, N 1, ст. 16.

4. Закон РФ о поправке к Конституции Российской Федерации от 14.03 .2020 г. № 1-ФКЗ «0 совершенствовании регулирования отдельных вопросов организации и функционирования публичной власти» // Собрание законодательства РФ. - 2020. - № 11. Ст. 1416.

5. Федеральный закон от 27.11.2018 N 422-Ф3 (в редакции от 08.06.2020) «0 проведении эксперимента по установлению специального налогового режима «Налог на профессиональный доход» в городе федерального значения Москве, в Московской и Калужской областях, а также в Республике Татарстан (Татарстан)» // «Российская газета», N 270, 30.11.2018.

6. Федеральный закон от 24.04.2008 N 48-Ф3 (в редакции от 08.12.2020) «06 опеке и попечительстве» // «Собрание законодательства РФ», 17.04.2008, N 17, ст. 1755.

7. Доходы, расходы и потребление домашних хозяйств в 2020 году (по итогам выборочного обследования бюджетов домашних хозяйств). Официальный сайт Федеральной службы государственной статистики. URL - https://rosstat.gov.ru/bgd/regl/b20_102/Main.htm.

8. Федеральный закон от 29.12.2006 N 256-Ф3 (в редакции от 22.12.2020) «0 дополнительных мерах государственной поддержки семей, имеющих детей» 
// «Российская газета», N 297, 31.12.2006.

9. Постановление администрации Владимирской области от 25.01 .2021 № 25 «0 порядке финансирования и расходования средств областного бюджета на государственное обеспечение и социальную поддержку детей-сирот и детей, оставшихся без попечения родителей, лиц из числа детей-сирот и детей, оставшихся без попечения родителей. Официальный интернет-портал правовой информации. Владимирская область. URL-http://publication.pravo.gov. $\mathrm{ru} /$ Document/View/3300202101250003.

( Кузнецова Наталья Владимировна (kuznezova-1963@mail.ru), Рябова Ольга Алексеевна (frau.lelya2012@yandex.ru ), Кованов Евгений Сергеевич.

Журнал «Современная наука: актуальные проблемы теории и практики»
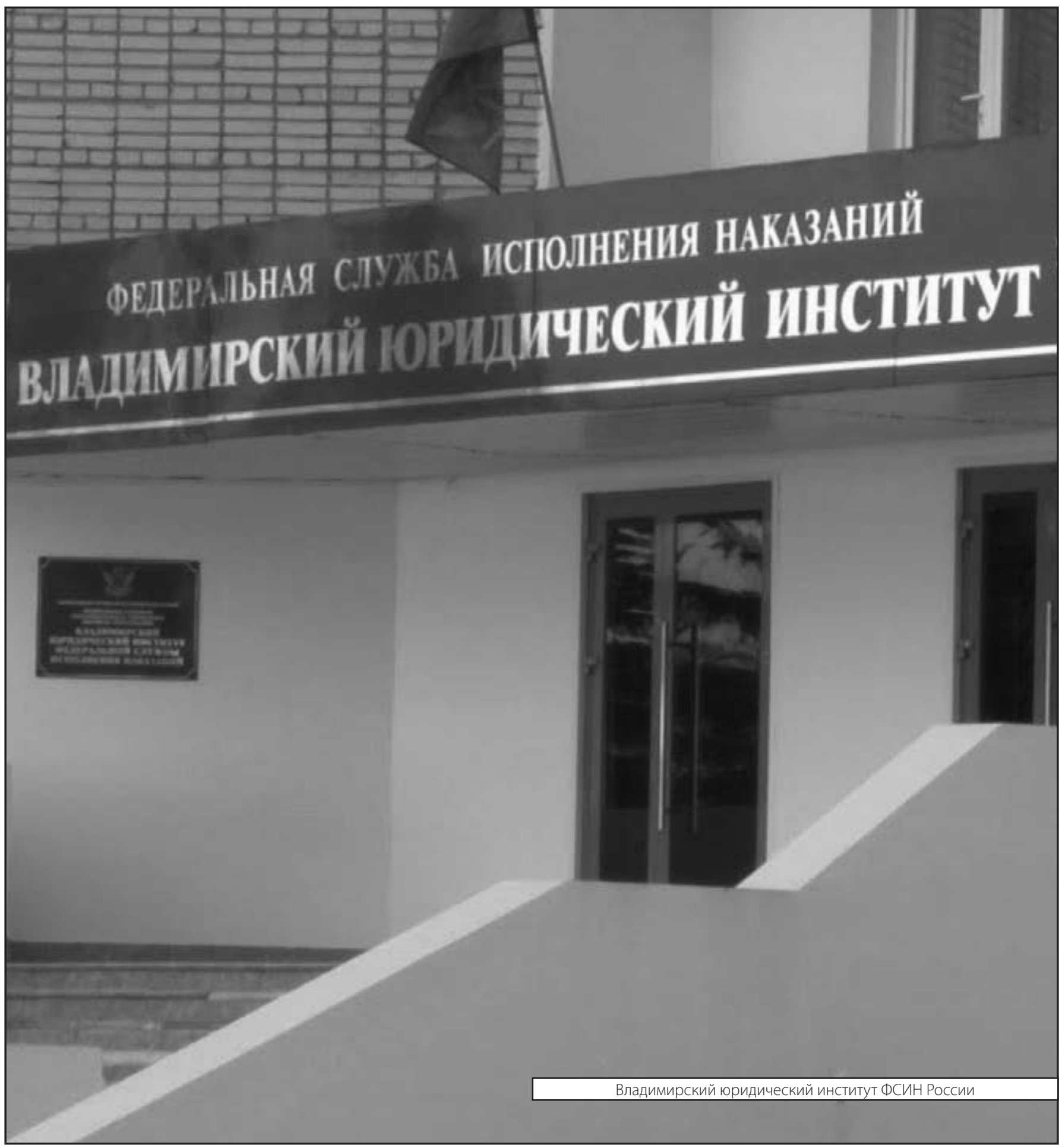